\title{
ИНТЕГРАЦИЯ АНСАМБЛЕВЫХ МЕТОДОВ МАШИННОГО ОБУЧЕНИЯ В СИСТЕМЫ ПОДДЕРЖКИ ПРИНЯТИЯ РЕШЕНИЙ
}

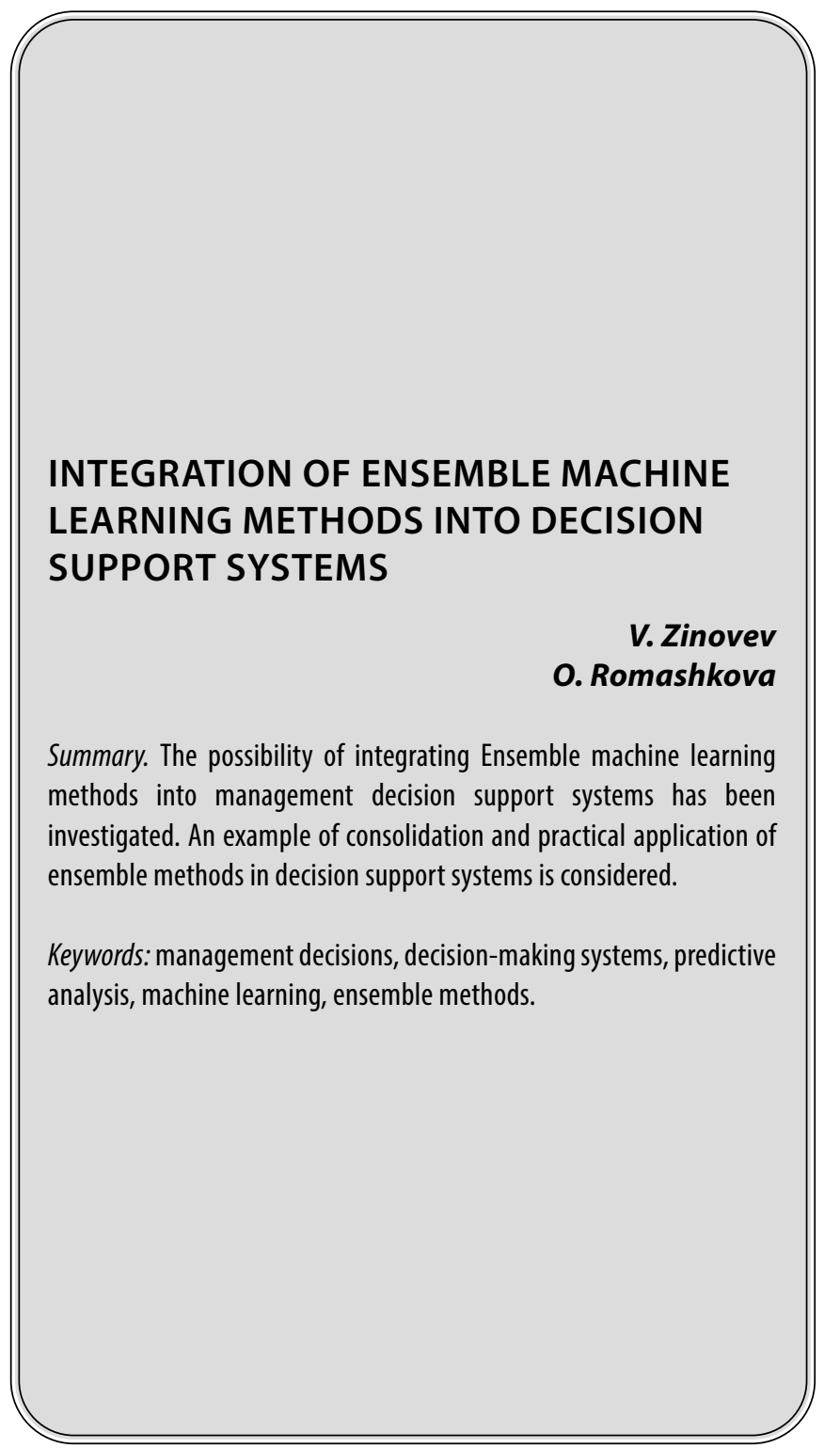

\section{Введение}

редиктивная аналитика является одним из самых важных аспектов в управленческой деятельности, так как на основе полученных прогнозов, ежедневно в той или иной отрасли принимаются управленческие решения, которые влияют как на отдельные показатели в существующих бизнес-процессах, так и на общие показатели в организации [1-3]. В подобных случаях, даже небольшой неправильно интерпретируемый показатель в отдельном сегменте бизнес-процес-
Зиновьев Владимир Иванович

Аспирант, ГАОУ ВО «Московский городской педагогический университет (МГПУ)» г. Москва legrang@yandex.ru

Ромашкова Оксана Николаевна

Д.т.н., профессор, ГАОУ ВО «Московский городской педагогический университет (МГПУ)», г. Москва

ox-rom@yandex.ru

Аннотация. Исследована возможность интеграции ансамблевых методов машинного обучения в системы поддержки принятия управленческих решений. Рассмотрен пример консолидации и практического применения ансамблевых методов в системах поддержки принятия решений.

Ключевые слова: управленческие решения, системы принятия решений, предиктивный анализ, машинное обучение, ансамблевые методы. са может привести к непредсказуемым последствиям на любом уровне.

Несмотря на бурный рост технологий предиктивного анализа, основная часть управленческих решений на практике до сих пор принимается на основе сводных выгрузок существующей ВІ (Business intelligence) отчетности, отображающих реальные данные. Выгрузки в различных срезах данных анализируются. Далее выводятся ключевые показатели, на основе которых ведущие менеджеры организации формируют модели, 


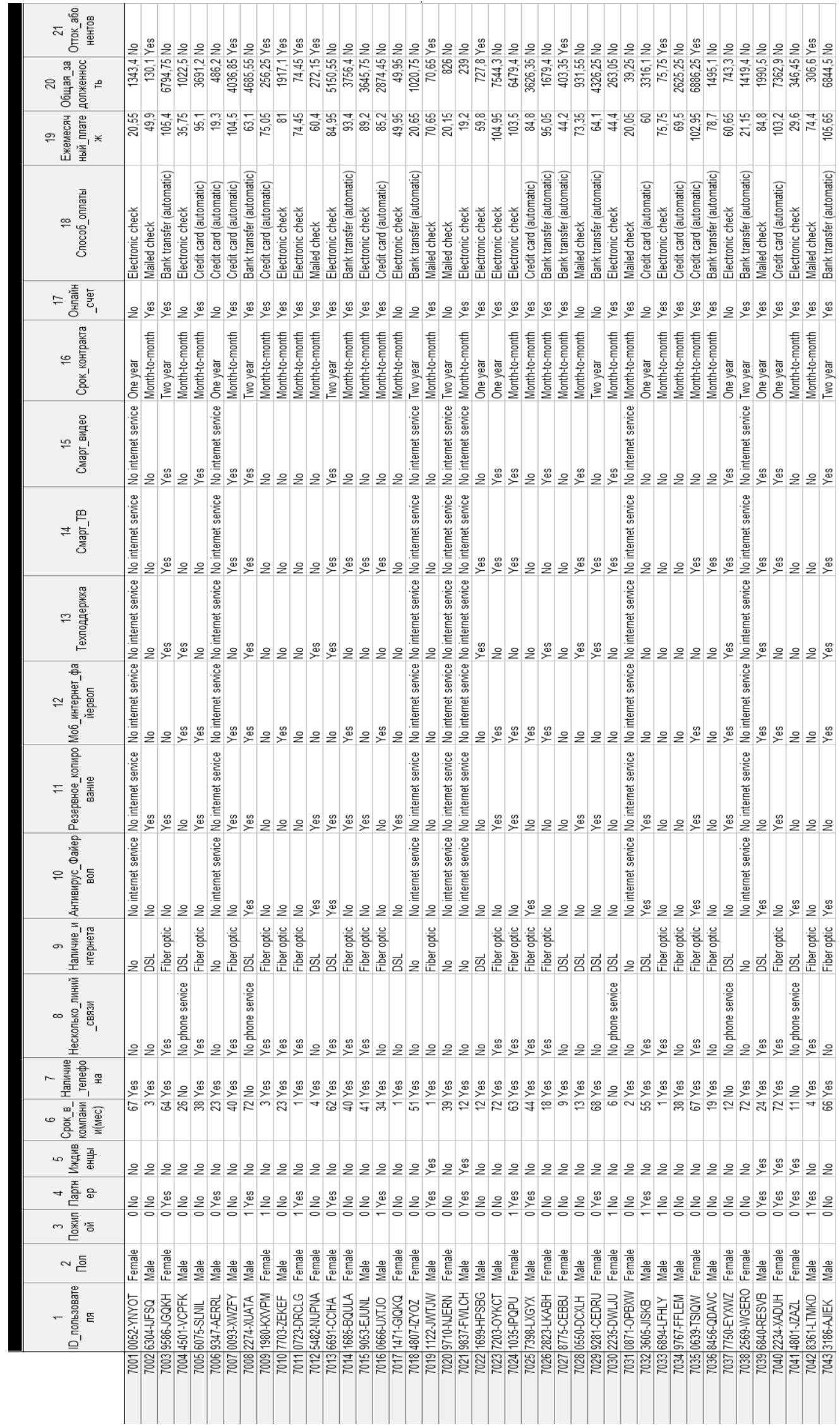

Рис. 1. Матрица данных 


\begin{tabular}{|c|}
\hline 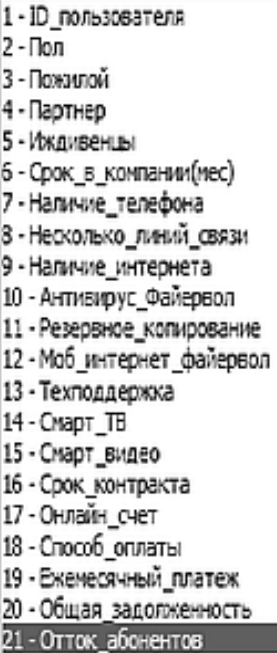 \\
\hline
\end{tabular}

\begin{tabular}{|l|l|}
\hline Spread Zoom \\
\hline
\end{tabular}

\begin{tabular}{|c|}
\hline 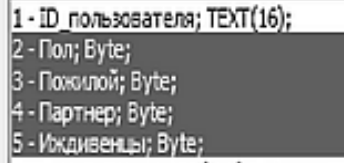 \\
\hline 6- Срок_ в_комาаниsi(vac); Integer; \\
\hline 7- Налиine_reredorta; Eyte; \\
\hline 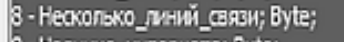 \\
\hline 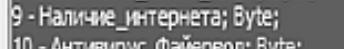 \\
\hline 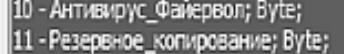 \\
\hline 12 - Mo6_yнтернет_фarepeon; Byte; \\
\hline 13 - Tехподаерков; Byte; \\
\hline 14 - Chapt_IB; Byte; \\
\hline 15- Снарт видео: Byte: \\
\hline 16-Cрок контракта; Double; \\
\hline 17-OHnas̆h_cuet; Byte; \\
\hline 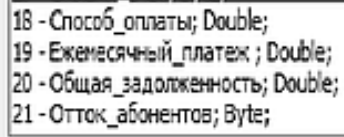 \\
\hline
\end{tabular}

\section{Shrink $200 \mathrm{~m}$}

Categorical predictors:

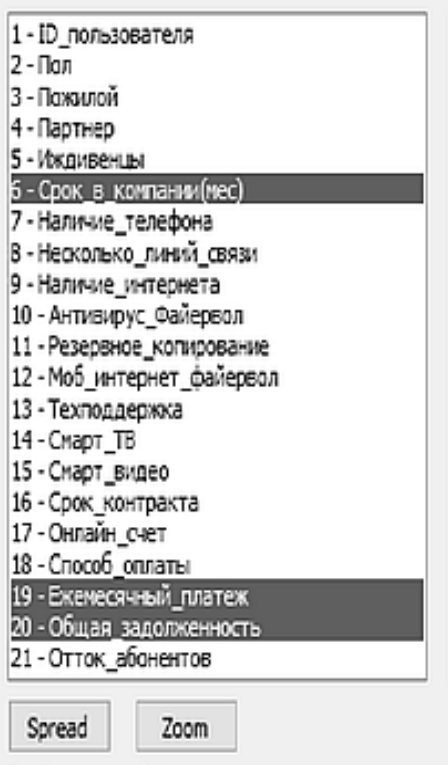

Continuous predictors:

\begin{tabular}{|c|c|}
\hline 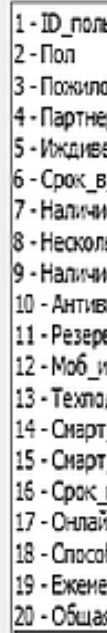 & 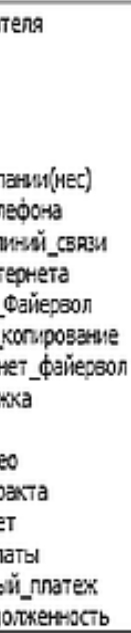 \\
\hline Spread & zoom \\
\hline
\end{tabular}

Рис. 2. Выбор признаков

позволяющие в той или иной степени спрогнозировать спад или подъем ключевых факторов $[4,5]$. Иными словами, большая часть прогнозных сводок зависит от экспертного уровня того или иного сотрудника. Помимо этого, текущие и ретроспективные аналитические выкладки не помогают увеличить процент уровня валидности предикторов, так как не учитывают регрессионные коэффициенты линейных и нелинейных комбинаций, при определении прогнозной функции. Стандартизированные же функции приводят к низкому уровню предиктивного анализа. Адаптация моделей хоть и дает некоторые улучшения, но при любом отклонении в исходных параметрах, увеличивает дисперсию случайной величины, пропорционально уровню изменений в исходных предикторах [6, 7].

Для повышения уровня прогнозной аналитики, экстраполяция предикторов функции должна учитывать ориентированные графы семантических сетей на уровнях: ретроспективных критериев и закономерностей; существующих факторов, с учетом их ранжирования; комбинаторных моделей аналитических прогнозов. Помимо этого, уровень корректности прогноза зависит от уровня объема и качества входной информации, а также выбора необходимого алгоритма (или комбинации алгоритмов), в рамках используемого метода, при решении конкретной задачи. Конкатенация вышеперечисленных семантических графов в правильной последовательности, приводит к формированию валидных результатов при прогнозировании $[8,9]$. На основе полученных результатов процесс принятия управленческих решений (как в долгосрочной, так и в краткосроч- ной перспективах) будет приносить положительную динамику роста показателей в организации.

\section{1. Выбор Ансамблевых методов машинного обучения $\triangle \wedge$ принятия управленческих решений}

Основные направления в системах поддержки принятия решений (СППР) предполагают формирование выводов, основанных или на правилах (rules), или на прецедентах (cases). Это означает, что чем ниже уровень формализации задачи (в результате недостаточности или некорректности данных), тем выше уровень дисперсии. Ансамблевая система методов принятия управленческих решений предполагает возможность формирования результатов прогноза в условиях, когда существующего количества rules или cases недостаточно для полноценного проведения машинного анализа существующих данных. На основе предварительных изысканий в исследуемой области $[10,11]$, в качестве предиктивной модели будут использоваться контролируемые методы обучения консолидированной связки алгоритмов «Случайный лес» (далее Random Forest) и Градиентный бустинг (далее Gradient Boosting). Random Forest представляет из себя множество принимающих решения деревьев, в виде таксономической классификации графа, декомпозируемого на интерпретируемые в процессе обучения признаки. Random Forest был выбран в качестве моделирования прогнозных предикторов в связи с тем, что он максимально соответствует основному принципу ансамблирования, а также одинаково эффективен как в задачах класси- 


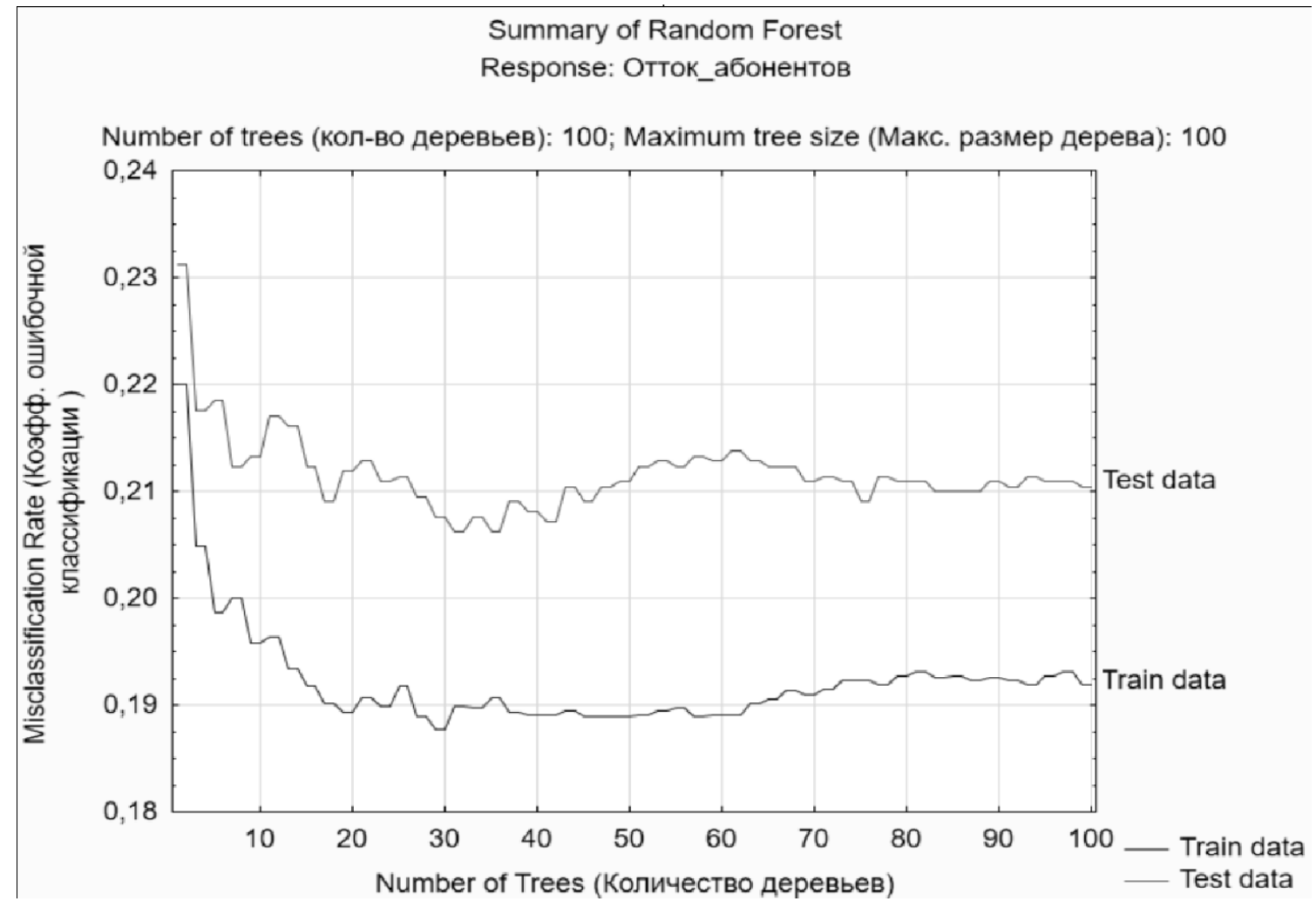

Рис. 3. Обучение модели

Importance plot (Важность)

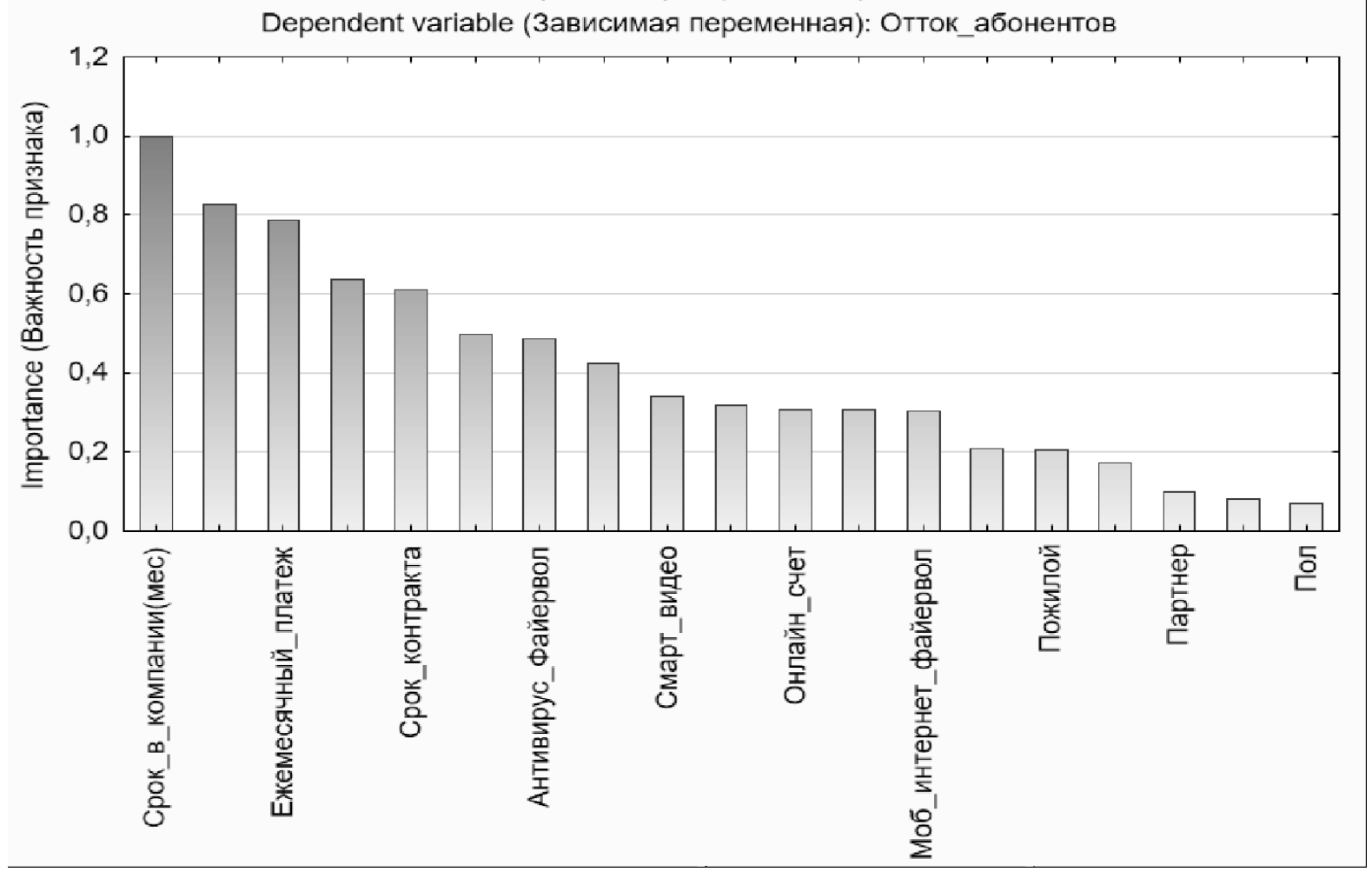

Рис. 4. Важность признака 


\begin{tabular}{|l|r|r|}
\hline \multirow{2}{*}{} & \multicolumn{2}{|c|}{$\begin{array}{l}\text { Predictor importance - Важность предиктора (Customer_sta) } \\
\text { Response: Oтт_абонентов }\end{array}$} \\
\cline { 2 - 3 } & $\begin{array}{c}\text { Variable } \\
\text { Rank }\end{array}$ & Importance \\
\hline Срок_в_компании(мес) & 100 & 1,000000 \\
\hline Общая_задолженность & 83 & 0,825526 \\
\hline Ежемесячныи_платеж & 79 & 0,787593 \\
\hline Наличие_интернета & 64 & 0,636705 \\
\hline Срок_контракта & 61 & 0,612791 \\
\hline Способ_оплаты & 50 & 0,498522 \\
\hline Антивирус_Файервол & 49 & 0,487351 \\
\hline Техподдержка & 42 & 0,423808 \\
\hline Смарт_видео & 34 & 0,338972 \\
\hline Смарт_ТВ & 32 & 0,320283 \\
\hline Онлайн_счет & 31 & 0,309611 \\
\hline Резервное_копирование & 31 & 0,309388 \\
\hline Моб_интернет_файервол & 30 & 0,303941 \\
\hline Несколько_линийсвязи & 21 & 0,207844 \\
\hline Пожилой & 21 & 0,206187 \\
\hline Иждивенцы & 17 & 0,173988 \\
\hline Партнер & 10 & 0,097770 \\
\hline Наличие_телефона & 8 & 0,082400 \\
\hline Пол & 7 & 0,070920 \\
\hline
\end{tabular}

Рис. 5. Ранг признаков

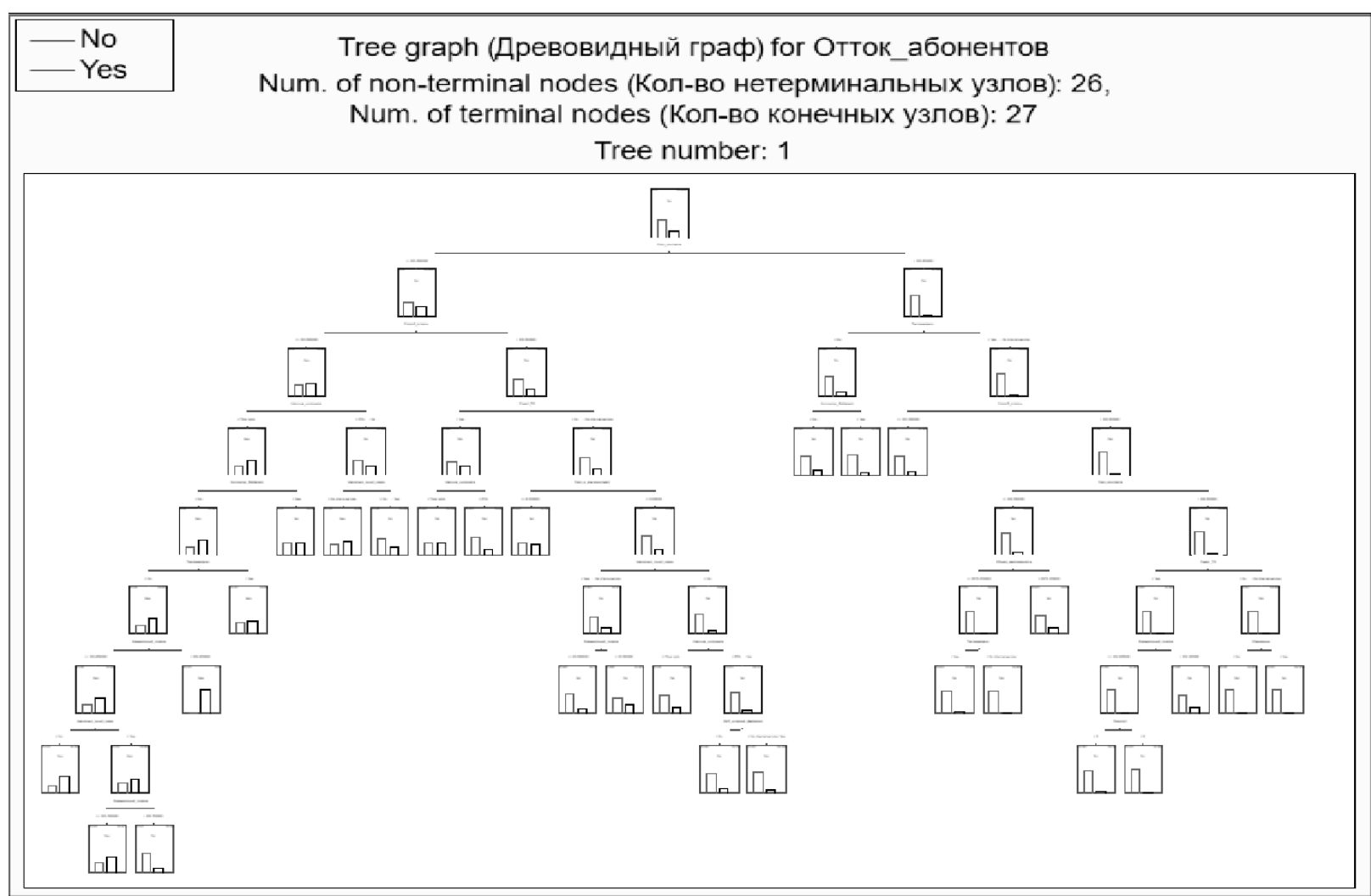

Рис. 6. Древовидный граф 


\begin{tabular}{|c|c|c|c|c|}
\hline & \multicolumn{4}{|c|}{$\begin{array}{l}\text { Classification matrix - Матрица классификации (Customer.sta) } \\
\text { Response: Oтток_aбонентов } \\
\text { Training set sample; Number of trees: } 200\end{array}$} \\
\hline & Observed & \begin{tabular}{c|} 
Class \\
Predicted No
\end{tabular} & \begin{tabular}{c|c|} 
Class \\
Predicted Yes
\end{tabular} & Row Total \\
\hline Number & No & 3344 & 263 & 3607 \\
\hline Column Percentage (Столбец Процент) & & $82.90 \%$ & $29.92 \%$ & \\
\hline Row Percentage (Строка Процент) & & $92.71 \%$ & $7.29 \%$ & \\
\hline Total Percentage (Итоговый процент) & & $68.06 \%$ & $5.35 \%$ & $73.42 \%$ \\
\hline Number & Yes & 690 & 616 & 1306 \\
\hline Column Percentage (Столбец Процент) & & $17.10 \%$ & $70.08 \%$ & \\
\hline Row Percentage (Строка Процент) & & $52.83 \%$ & $47.17 \%$ & \\
\hline Total Percentage (Итоговый процент) & & $14.04 \%$ & $12.54 \%$ & $26.58 \%$ \\
\hline Count (Итоговый расчет по группам) & All Groups & 4034 & 879 & 4913 \\
\hline Total Percent (Итоговый процент) & & $82.11 \%$ & $17.89 \%$ & \\
\hline
\end{tabular}

Рис. 7. Матрица классификации

фикационного, так и в задачах регрессионного анализа [12]. Основной концепцией эффективности алгоритма Gradient Boosting является способность обучения на ошибках предыдущей модели. Для этого Gradient Boosting создает ансамбль предикторов, и формирует функцию потерь, плавно производя ее минимизацию.

\section{2. Практическое применение комбинации а^горитмов Random \\ Forest $и$ Gradient Boosting в системаx по $\triangle$ ержки принятия решений}

В качестве практического примера реализации, подготовлены и загружены данные, содержащие статистику оттока абонентов компании Интернет-провайдера (рисунок 1). Атрибуты столбцов представляют следующие характеристики: «ID_пользователя»-уникальный идентификатор пользователя; «Пол» - пол абонента; «Пожилой» - бинарный признак, определяющий возрастной критерий; «Партнер» - бинарный признак, определяющий семейный статус абоненты; «Иждивенцы» - бинарный признак, определяющий наличие детей, или иждивенцев абонента; «Срок_в_компании(мес)» - числовой признак, определяющий колво месяцев, которое абонент беспрерывно является, или являлся клиентом провайдера; «Наличие телефона» - бинарный признак, определяющий, является ли клиент провайдера телефонным абонентом; «Несколько_линий_связи» - признак, отображающий наличие нескольких линий связи; «Наличие_интернета» - при- знак, отображающий наличие и тип интернет линии; «Антивирус_файервол» - признак, отображающий наличие подключенной услуги антивируса, сетевого экрана; «Резервное_копирование» - признак, отображающий наличие подключенной услуги резервного копирования данных; «Моб_интернет_файервол» - признак, отображающий наличие подключенной услуги мобильного интернета, или файервола; «Техподдержка» - признак, отображающий наличие подключенной услуги техподдержки; “Смарт_ТВ» - признак, отображающий наличие подключенной услуги цифрового телевидения; «Смарт_видео» - признак, отображающий наличие подключенной услуги цифрового видео контента; «Срок_контракта» - признак, отображающий срок контракта абонента и провайдера; «Онлайн_ счет» - признак, отображающий регистрацию пользователя в системе, для совершения онлайн платежей; «Способ_оплаты» - признак, отображающий предпочитаемый тип оплаты для каждого абонента; «Ежемесячный_платеж» - признак, отображающий размер ежемесячного платежа абонента; «Общая_задолженность» - признак, отображающий наличие задолженности по счетам абонента; «Отток_абонента» - бинарный признак, отображающий отказ текущего абонента от услуг провайдера.

На первом этапе построения модели был применен алгоритм Random Forest. Была произведена декомпозированная выборка: Зависимого признака, Категориальных признаков, Непрерывных признаков (рисунок 2). 
Lift Chart (Диаграмма точности прогнозов) - Lift value (Точность прогнозов)

Cumulative - Накопительный; Category: No

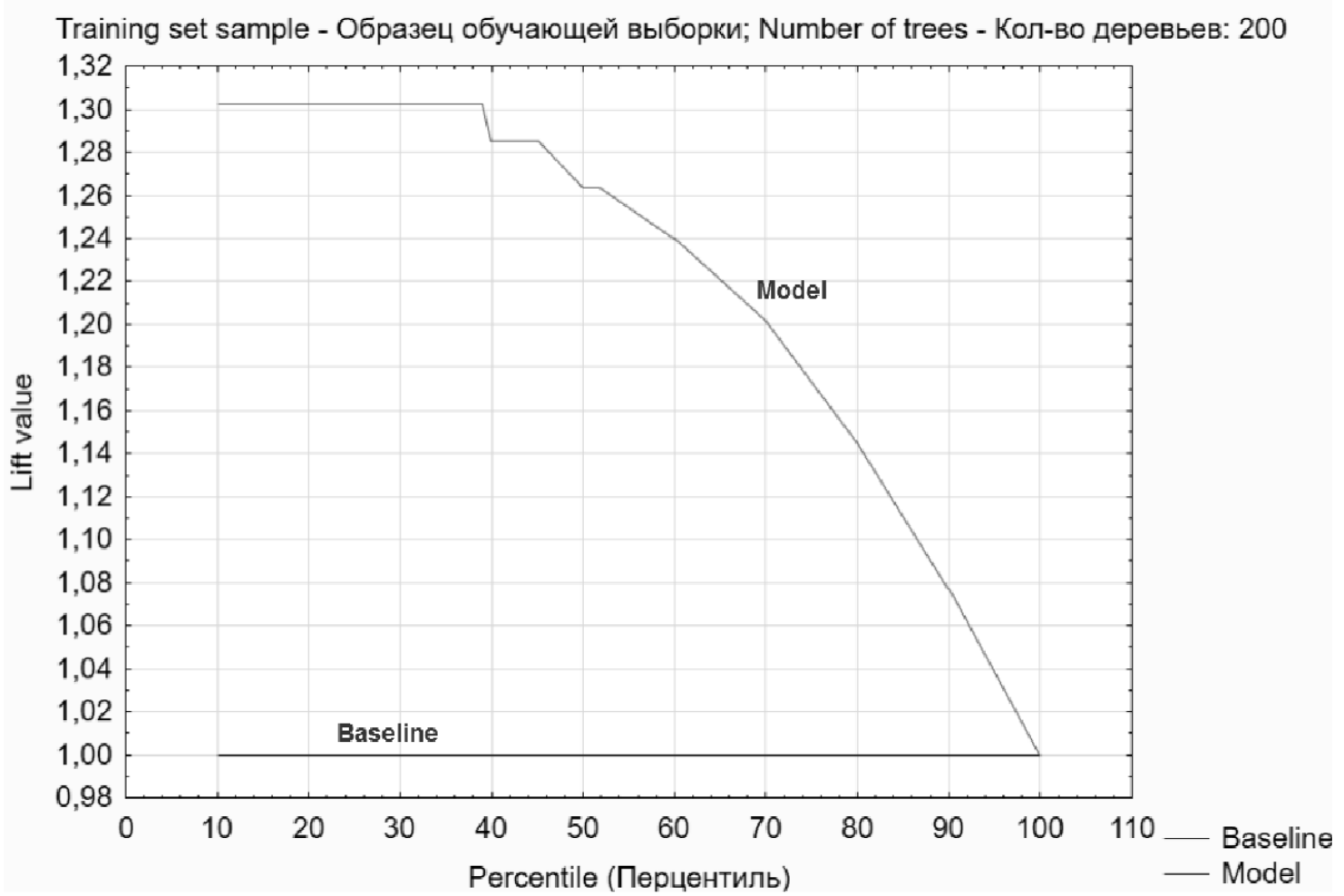

Lift Chart (Диаграмма точности прогнозов) - Lift value

Cumulative (Накопительный); Category: Yes

Training set sample - Образец обучающей выборки; Number of trees - Кол-во деревьев: 200

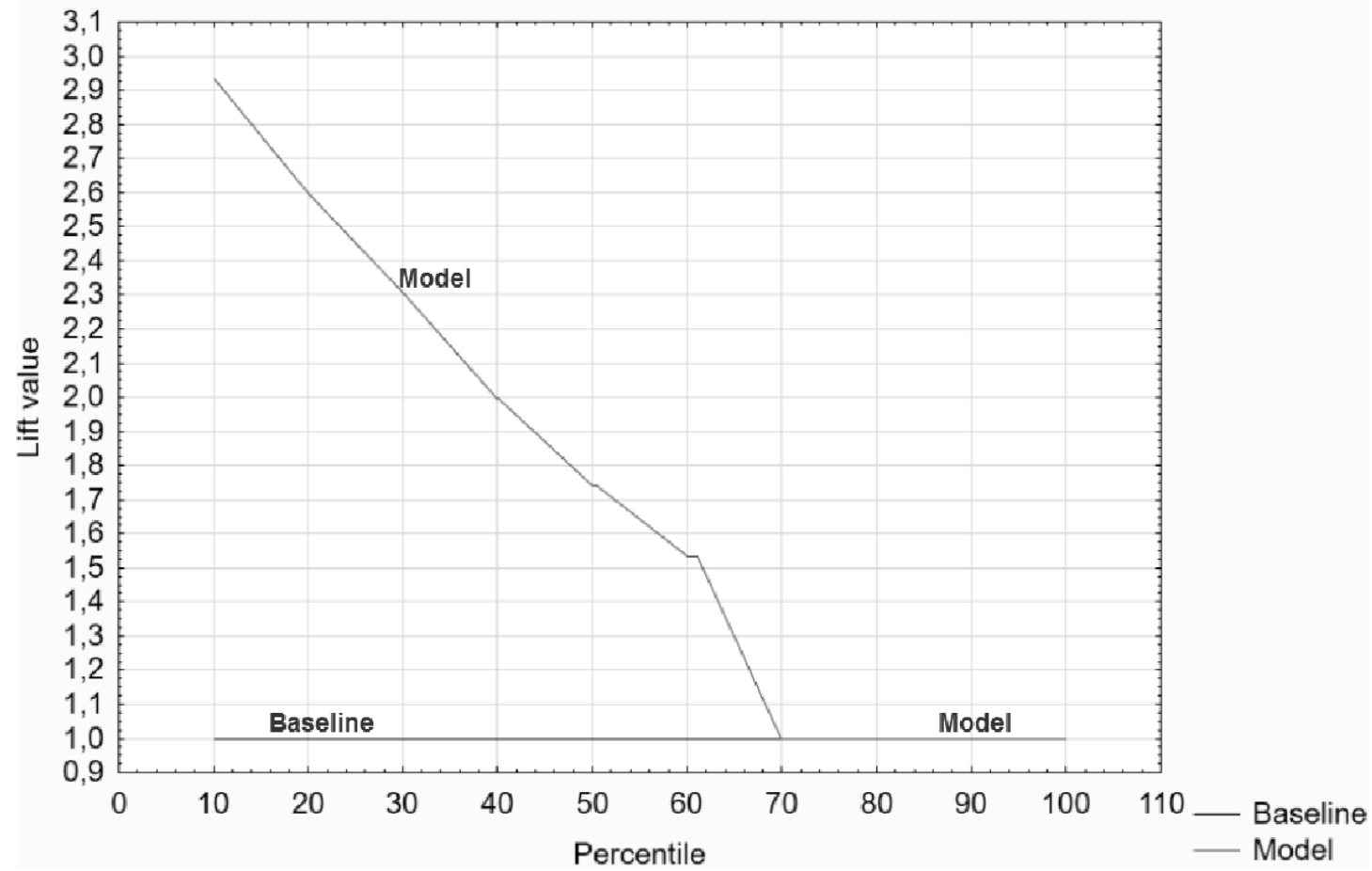

Рис. 8. Диаграмма точности прогнозов 
Classification matrix (Матрица классификации)

Training set sample (Образец обучающего набора); Number of trees (Кол-во деревьев): 200

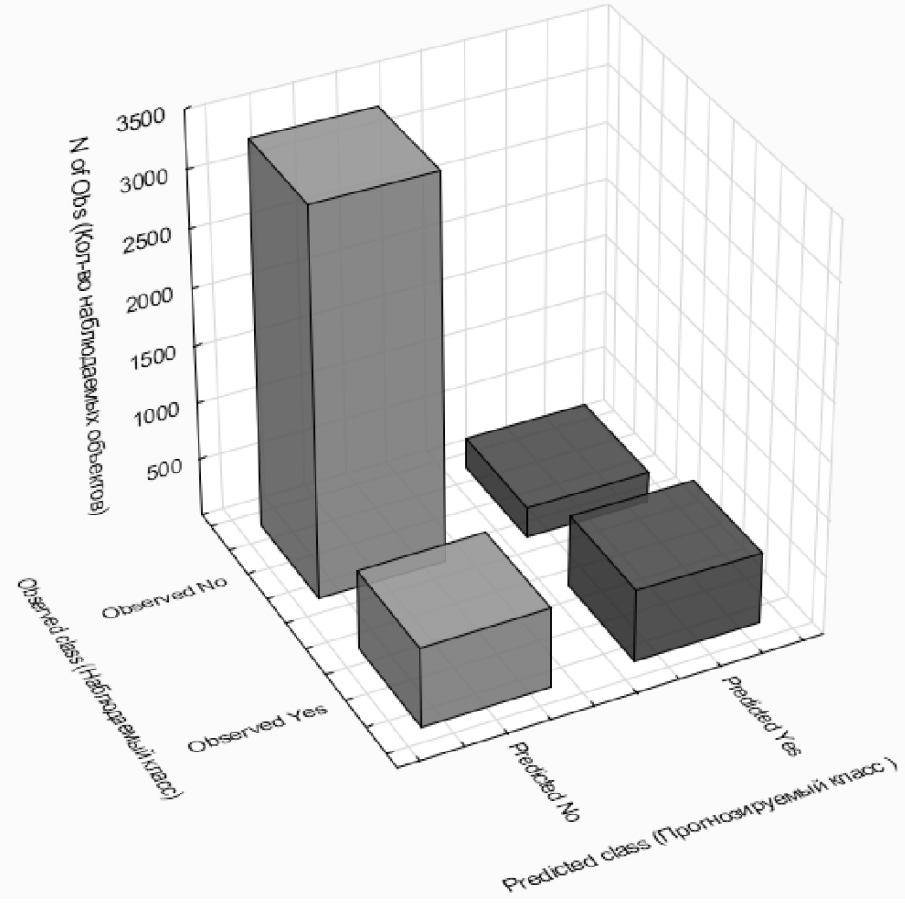

Рис. 9. Столбиковая диаграмма матрицы классификации

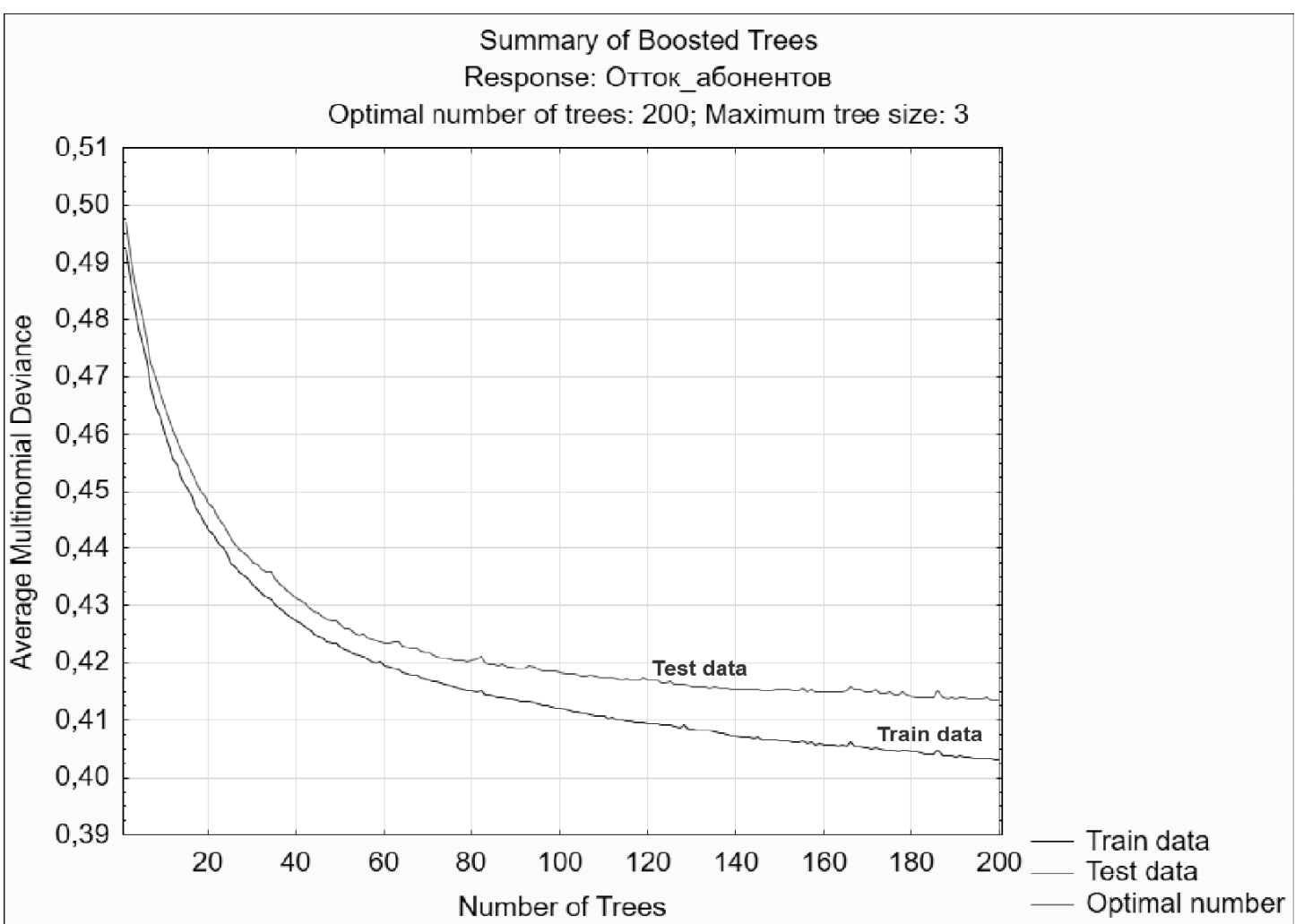

Рис. 10. Обучение модели 


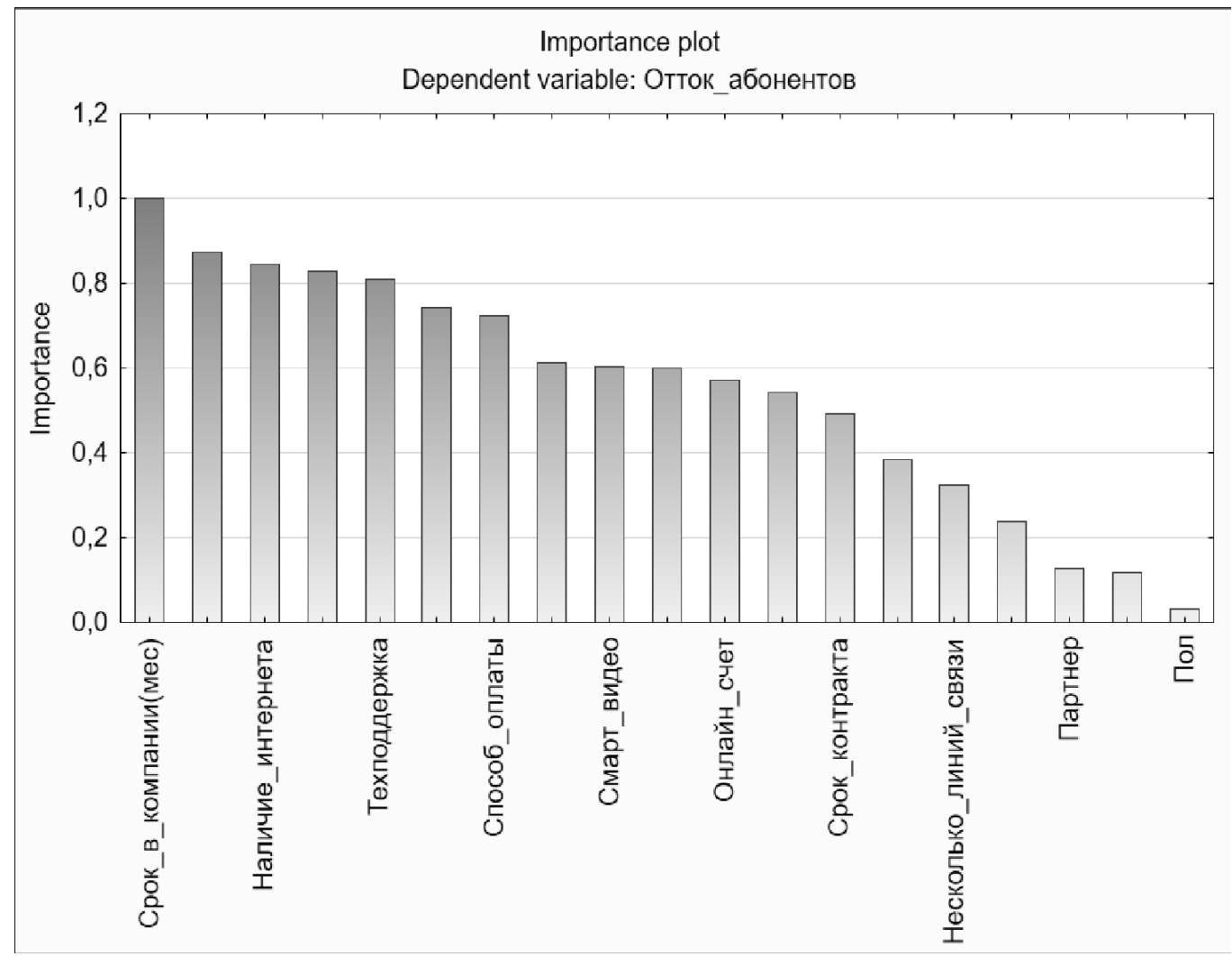

Рис. 11. Важность признака

\begin{tabular}{l|r|r|} 
& \multicolumn{2}{|c|}{$\begin{array}{l}\text { Predictor importance (Customer_sta) } \\
\text { Response: Oток_а6онентов }\end{array}$} \\
\cline { 2 - 3 } & $\begin{array}{c}\text { Variable } \\
\text { Rank }\end{array}$ & \multicolumn{1}{|c|}{ Importance } \\
\hline Срок_в_компании(мес) & 100 & 1,000000 \\
\hline Антивирус_Файервол & 87 & 0,874304 \\
\hline Наличие_интернета & 85 & 0,845102 \\
\hline Ежемесячный_платеж & 83 & 0,828819 \\
\hline Техподдержка & 81 & 0,809696 \\
\hline Общая_задолженность & 74 & 0,741701 \\
\hline Спосаб_оплаты & 72 & 0,724640 \\
\hline Смарт_ТВ & 61 & 0,612892 \\
\hline Смарт_видео & 60 & 0,604784 \\
\hline Резервное_копирование & 60 & 0,599122 \\
\hline Онлайн_счет & 57 & 0,572783 \\
\hline Моб_интернет_файервол & 54 & 0,544352 \\
\hline Срок_контракта & 49 & 0,493200 \\
\hline Пожилой & 38 & 0,384816 \\
\hline Несколько_линий_связи & 32 & 0,323587 \\
\hline Пждивенцы & 24 & 0,239210 \\
\hline Партнер & 13 & 0,126499 \\
\hline Наличие_телефона & 12 & 0,118921 \\
\hline Пол & 3 & 0,032816 \\
\hline
\end{tabular}

Рис. 12. Ранг признаков 
Tree graph for Отток_абонентов

Num. of non-terminal nodes: 1 , Num. of terminal nodes: 2

Tree number: 1; Category: No

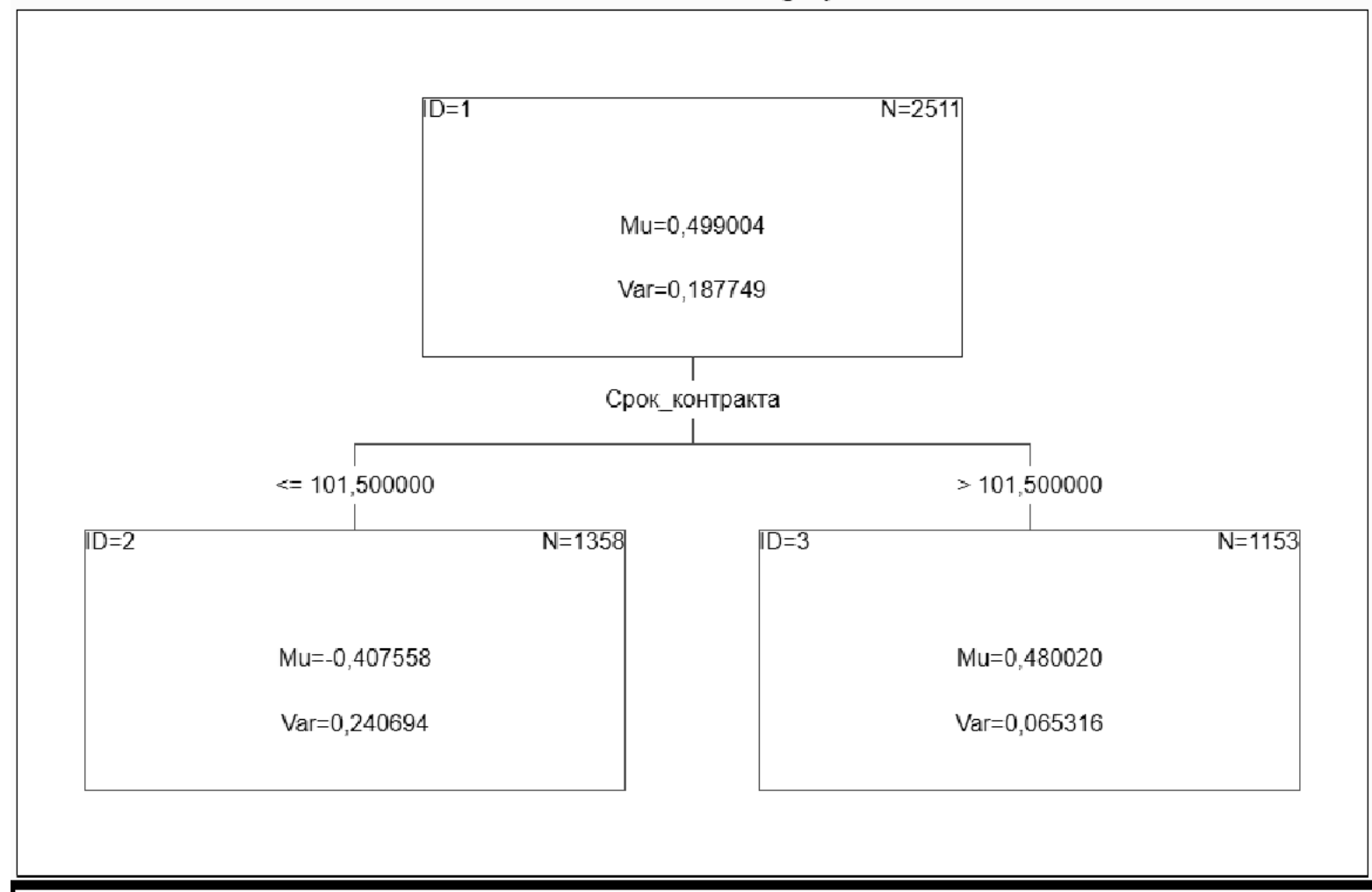

Tree graph for Отток_абонентов

Num. of non-terminal nodes: 1, Num. of terminal nodes: 2

Tree number: 1; Category: Yes

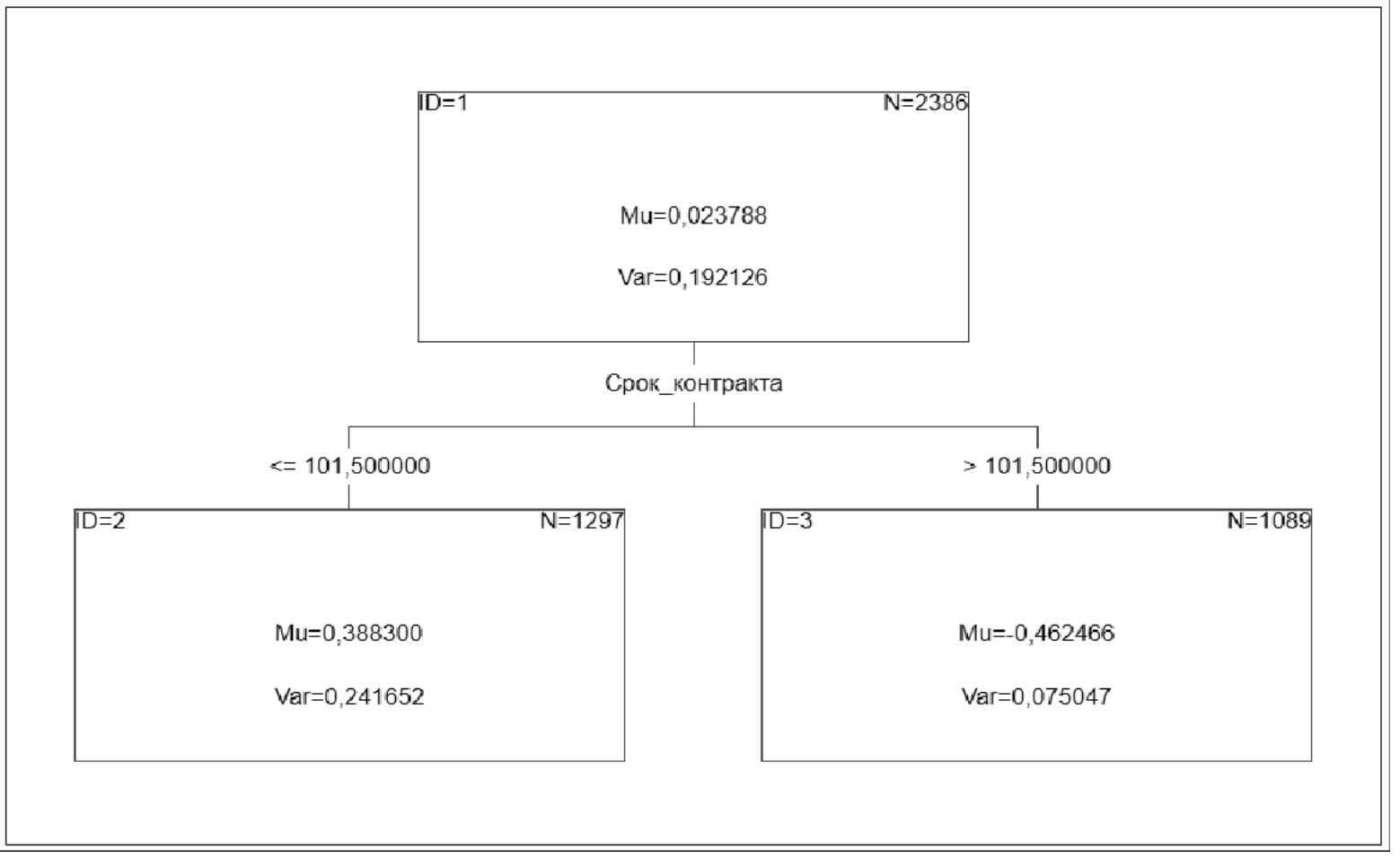

Рис. 13. Дерево графов 


\begin{tabular}{|c|c|c|c|c|}
\hline & \multicolumn{4}{|c|}{$\begin{array}{l}\text { Classification matrix - Матрица классификации (Customer_sta) } \\
\text { Response: Oтток_абонентов } \\
\text { Analysis sample;Number of trees: } 200\end{array}$} \\
\hline & Observed & Predicted No & Predicted Yes & Row Total \\
\hline Number & $\mathrm{No}_{0}$ & 2690 & 971 & 3661 \\
\hline Column Percentage (Столбец Процент) & & $91.68 \%$ & $48.26 \%$ & \\
\hline Row Percentage (Строка Процент) & & $73.48 \%$ & $26.52 \%$ & \\
\hline Total Percentage (Итоговый процент) & & $54.39 \%$ & $19.63 \%$ & $74.02 \%$ \\
\hline Number & Yes & 244 & 1041 & 1285 \\
\hline Column Percentage (Столбец Процент) & & $8.32 \%$ & $51.74 \%$ & \\
\hline Row Percentage (Строка Процент) & & $18.99 \%$ & $81.01 \%$ & \\
\hline Total Percentage (Итоговый процент) & & $4.93 \%$ & $21.05 \%$ & $25.98 \%$ \\
\hline Count (Итоговый расчет по группам) & All Groups & 2934 & 2012 & 4946 \\
\hline Total Percent (Итоговый процент) & & $59.32 \%$ & $40.68 \%$ & \\
\hline
\end{tabular}

Рис. 14. Матрица классификации

Далее произведено обучение модели, с построением таксономической структуры обучающих деревьев (рисунок 3), на которой в качестве оси ординат у выступает расчет степени коэффициента ошибочной классификации, в качестве оси абсцисс х выступает обучающая выборка (количество деревьев).

В конце процесса обучения модели оценка риска соотношений тренировочной и тестовой выборок в исчисляемом эквиваленте составляла 0,192323314378554 к 0,209532798489854, стандартное отклонение ошибки составило 0,00561662874919609 к 0,00884102168259427.

Построен график градации важности признаков, на котором по оси ординат отложены результаты расчета коэффициента важности признака, а по оси абсцисс отмечены анализируемые признаки (рисунок 4).

Важность анализируемых предикторов можно представить в табличном виде (рисунок 5).

Построен древовидный граф с рассчитанным количеством нетерминальных узлов, а также конечных узлов (рисунок 6).

Сформирована матрица классификации (рисунок 7), на которой отображены процентные соотношения предсказанных результатов и расхождения между реальными данными по оттоку абонентов.

По результатам предварительного анализа, процент предсказанного оттока абонентов (Category = «Yes») недостаточно хорош (рисунок 8).
На графике трехмерной столбиковой диаграммы соотношения наблюдаемого и прогнозируемого классов выглядят следующим образом (рисунок 9).

Применим к модели алгоритм Gradient Boosting и продолжим обучение. После завершения обучения модели снова построим таксономическую структуру обучающих деревьев, и сразу же увидим изменения в динамике. Кривые обучения более плавные и без скачков. Причем кривая обучения максимально приближена к результатам тестовых данных (рисунок 10).

Оценка риска соотношений тренировочной и тестовой выборок в исчисляемом эквиваленте теперь составляет 0,245653052972099 к 0,252265140677158, стандартное отклонение ошибки составляет 0,00612096076138834 к 0,00948425494103256. При построении нового графика градации важности признаков параметры меняются (рисунок 11).

Важность анализируемых предикторов теперь выглядит иначе (рисунок 12).

Построим дерево графов для предикторов градиентного бустинга (рисунок 13).

Итоговая матрица классификации теперь изменилась. Процент предсказанных значений по признаку «Отток_абонентов» сильно увеличился (рисунок 14).

На диаграмме точности прогнозов процент предсказанного оттока абонентов максимально приблизился наивысшим положительным показателям (рисунок 15). 
Lift Chart (Диаграмма точности прогнозов) - Lift value (Точность прогнозов) Cumulative - Накопительный; Category: No

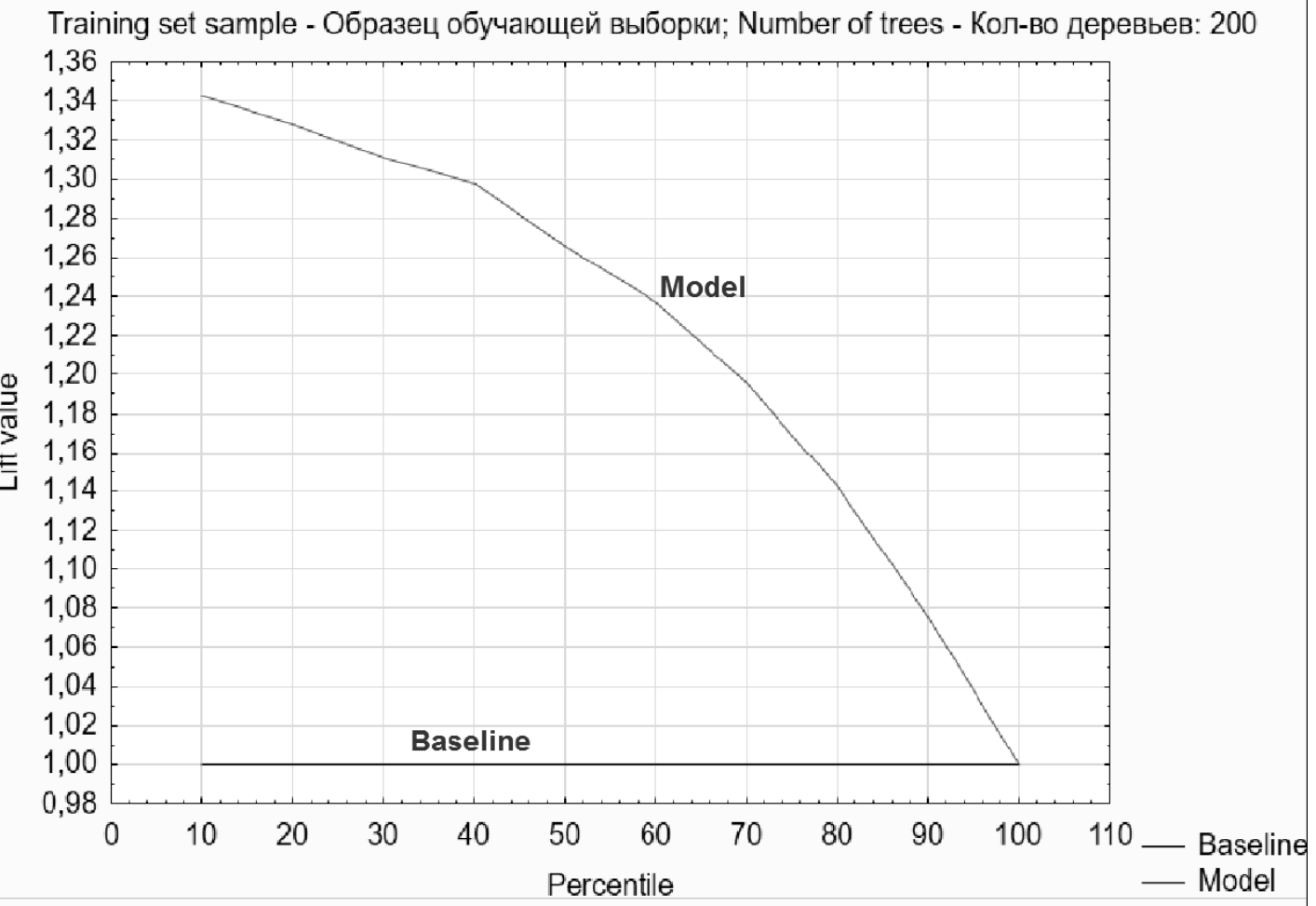

Lift Chart (Диаграмма точности прогнозов) - Lift value

Cumulative (Накопительный); Category: Yes

Training set sample - Образец обучающей выборки; Number of trees - Кол-во деревьев: 200

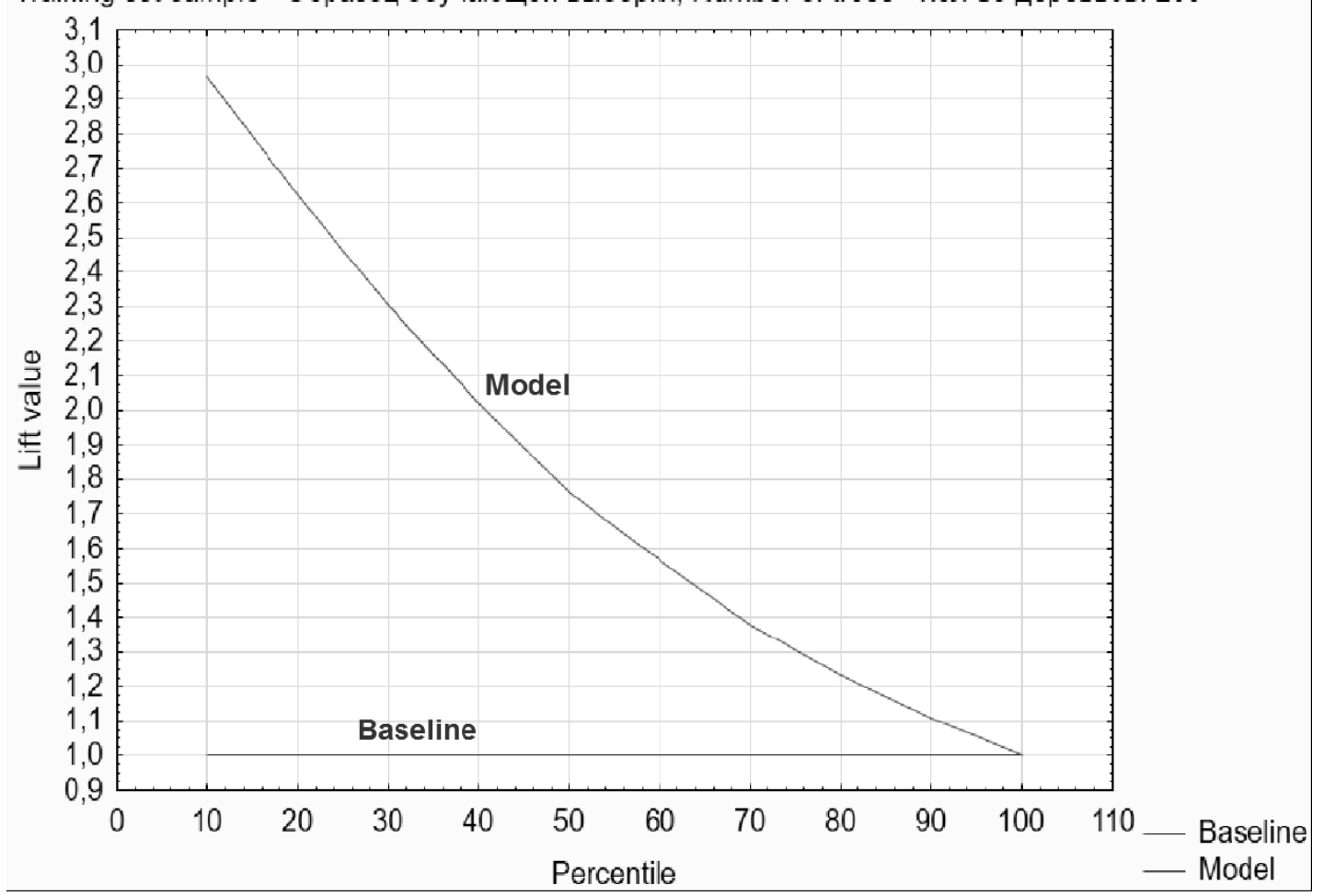

Рис. 15. Диаграмма точности прогнозов 


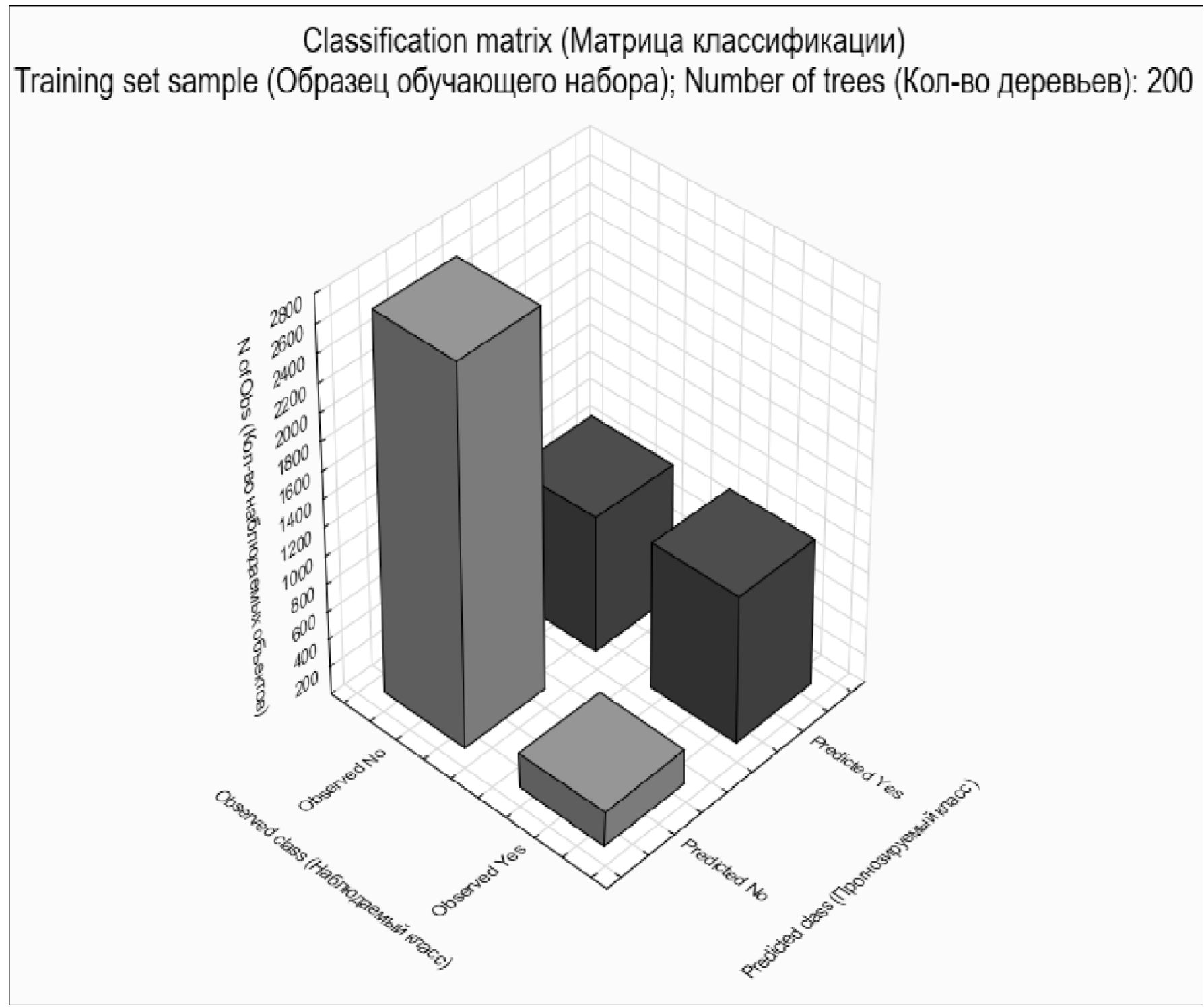

Рис. 16. Столбиковая диаграмма матрицы классификации

Построим столбиковую диаграмму соотношения наблюдаемого и прогнозируемого классов (рисунок 16), на которой видно, что предсказанные моделью результаты почти совпадают с тестовыми данными.

На примере отрезка фактической выгрузки результатов сравнения наблюдаемых и предсказанных значений видно (рисунок 17), что все ошибки модели связаны с излишней осторожностью, что нивелируется дополнительными настройками модели. При этом, основную задачу выявления каналов потенциального оттока клиентов можно считать успешно завершенной.

Далее осуществляем связку полученных результатов с признаком «ID_пользователя», а также сбор ранжированных признаков с количественными ха- рактеристиками, которые влияют на отток абонентов. Данные передаются в формате JSON для метода API, и в требуемом формате визуализируются для бизнес-аналитиков предприятия. В результате эффективность принятия правильных управленческих решений возрастает. Для абонентов, теряющих лояльность компании, могут быть предоставлены новые услуги или реорганизованы текущие. Также производится фокусировка на внутренних бизнес-процессах и услугах компании, которые не отвечают конъюнктуре существующих реалий.

\section{Зак^ючение}

Таким образом, проведено исследование возможности интеграции ансамблевых методов машинного обу- 


\begin{tabular}{|c|c|c|c|c|}
\hline & \multicolumn{4}{|c|}{$\begin{array}{l}\text { Predicted values (Customer_sta) } \\
\text { Response: Oток_абонентов } \\
\text { Analysis sample;Number of trees: } 200\end{array}$} \\
\hline & $\begin{array}{c}\text { Observed } \\
\text { (Набпюдаем } \\
\text { ое) } \\
\text { value }\end{array}$ & \begin{tabular}{|c|} 
Predicted \\
(Предсказан \\
ное) \\
value
\end{tabular} & $\begin{array}{c}\text { Probability } \\
\text { (Вероятность) for } \\
\text { No }\end{array}$ & $\begin{array}{c}\text { Probability } \\
\text { (Вероятность) for } \\
\text { Yes }\end{array}$ \\
\hline$\overline{5591}$ & No & No & 0,810932 & 0,189068 \\
\hline 5593 & No & No & 0,935654 & 0,064346 \\
\hline 5596 & No & No & 0,580759 & 0,419241 \\
\hline 5598 & Yes & Yes & 0,315133 & 0,684867 \\
\hline 5599 & No & No & 0,958397 & 0,041603 \\
\hline 5600 & Yes & Yes & 0,311336 & 0,688664 \\
\hline 5601 & Yes & Yes & 0,292992 & 0,707008 \\
\hline 5602 & No & No & 0,857896 & 0,142104 \\
\hline 5603 & No & No & 0,786445 & 0,213555 \\
\hline 5604 & Yes & Yes & 0,295958 & 0,704042 \\
\hline 5606 & No & No & 0,510757 & 0,489243 \\
\hline 5609 & No & No & 0,908840 & 0,091160 \\
\hline 5610 & Yes & Yes & 0,375589 & 0,624411 \\
\hline 5612 & No & Yes & 0,305759 & 0,694241 \\
\hline 5615 & No & No & 0,857326 & 0,142674 \\
\hline 5617 & No & No & 0,730691 & 0,269309 \\
\hline 5618 & No & No & 0,617957 & 0,382043 \\
\hline 5619 & No & No & 0,770054 & 0,229946 \\
\hline 5621 & No & No & 0,674240 & 0,325760 \\
\hline 5624 & No & No & 0,594861 & 0,405139 \\
\hline 5630 & Yes & Yes & 0,341584 & 0,658416 \\
\hline 5632 & No & Yes & 0,287866 & 0,712134 \\
\hline 5634 & No & No & 0,700159 & 0,299841 \\
\hline 5635 & Yes & Yes & 0,257306 & 0,742694 \\
\hline 5636 & No & No & 0,622114 & 0,377886 \\
\hline 5639 & Yes & Yes & 0,313191 & 0,686809 \\
\hline 5640 & No & No & 0,711250 & 0,288750 \\
\hline 5642 & No & No & 0,943279 & 0,056721 \\
\hline 5643 & No & No & 0,948575 & 0,051425 \\
\hline 5645 & Yes & Yes & 0,095378 & 0,904622 \\
\hline 5647 & Yes & No & 0,533465 & 0,466535 \\
\hline 5648 & No & No & 0,557012 & 0,442988 \\
\hline 5654 & Yes & Yes & 0,161514 & 0,838486 \\
\hline 5655 & No & No & 0,795096 & 0,204904 \\
\hline 5660 & No & No & 0,937082 & 0,062918 \\
\hline 5662 & No & Yes & 0,457713 & 0,542287 \\
\hline 5663 & Yes & Yes & 0,074561 & 0,925439 \\
\hline 5665 & Yes & Yes & 0,194510 & 0,805490 \\
\hline 5666 & No & No & 0,526718 & 0,473282 \\
\hline 5667 & No & No & 0,851328 & 0,148672 \\
\hline 5668 & No & No & 0,552026 & 0,447974 \\
\hline
\end{tabular}

Рис. 17. Сравнительные результаты 
чения в системы поддержки принятия управленческих решений. Рассмотрен пример консолидации и практического применения ансамблевых методов в системах поддержки принятия решений, на основании которого можно сделать выводы о степени точности прогнозных оценок, и возможности их применения на практике.

\section{ЛИТЕРАТУРА}

1. Хенрик Бринк, Джозеф Ричардс, Марк Феверолф. Машинное обучение. - Питер, 2017. - 336 c. ISBN: 978-5-496-02989-6.

2. Gorelov G.V., Kazanskii N.A., Lukova 0.N. Communication quality assessment in speech packet transmission networks with random service interrupts // Automatic Control and Computer Sciences. 1993., vol.27., no.1., p.62.

3. Пономарева Л.А., Ромашкова 0.Н., Василюк И.П. Алгоритм оценки эффективности работы кафедр университета для управления его рейтинговыми показателями // Вестник Рязанского государственного радиотехнического университета. 2018. № 64. С. 102-108.

4. Литвак Б.Г., Стефановский Д.В. Моделирование и построение глобального управленческого цикла // В книге: Управление развитием крупномасштабных систем (MLSD'2011). Материалы пятой международной конференции. 2011. С. 124-126.

5. Дж. Вандер Плас. Руthon для сложных задач. Наука о данных и машинное обучение. — Питер, 2018. — 575 c. ISBN: 978-5-496-03068-7.

6. Ромашкова 0.Н., Яковлев Р.И. Анализ моделей и методов для оценки живучести инфокоммуникационных сетей в условиях чрезвычайных ситуаций // Т-Соmm: Телекоммуникации и транспорт. 2012. Т. 6. № 7. С. 165-170.

7. Ромашкова 0.Н., Федин Ф.О., Ермакова Т.Н. Нейросетевая компьютерная модель для поддержки принятия решений в образовательных комплексах // Вестник Рязанского государственного радиотехнического университета. 2017. № 61. С. 54-59.

8. Dr. Anasse Bari, Mohamed Chaouchi, Tommy Jung. Predictive Analytics For Dummies // For Dummies; 2nd edition (0ctober 31, 2016). — 464 pages. ISBN10 8126567937 (ISBN13 978-1119267003).

9. Gaidamaka Y.V., Romashkova 0.N., Ponomareva L.A., Vasilyuk I.P. Application of information technology for the analysis of the rating of university // CEUR Workshop Proceedings 8. Cep. "ITTMM 2018 - Proceedings of the Selected Papers of the 8th International Conference "Information and Telecommunication Technologies and Mathematical Modeling of High-Tech Systems'"' 2018. C. 46-53.

10. Горелов Г.В., Ромашкова 0.Н. Оценка качества обслуживания в сетях с пакетной передачей речи и данных // Вестник Российского университета дружбы народов. Серия: Прикладная и компьютерная математика. 2003. Т. 2. № 1. С. 23-31.

11. Maimon 0. and Rockach L. (Eds.) Data Mining and Knowledge Discovery Handbook: A Complete Guide for Practitioners and Researchers," Published May 10th 2014 by Springer (first published January 1st 2005), ISBN1282980823 (ISBN13 9781282980822).

12. Ромашкова 0.Н., Федин Ф.0., Фролов П.А. Применение нейросетевых технологий для проверки благонадежности контрагентов сетевой торговой компании // Современная наука: актуальные проблемы теории и практики. Серия: Экономика и право. 2018. № 7. С. 126. 